\title{
A Imagem da Psicologia Organizacional e do Trabalho entre Estudantes de Psicologia: o Impacto de uma Experiência Acadêmica
}

The image of work and organizational Psychology among Psychology students: The impact of a teaching experience

Antonio Virgílio Bittencourt Bastos ,

José Henrique Miranda de Morais ,

Mariana Viana Santos \&

Ivan Faria

Universidade

Federal da Bahia

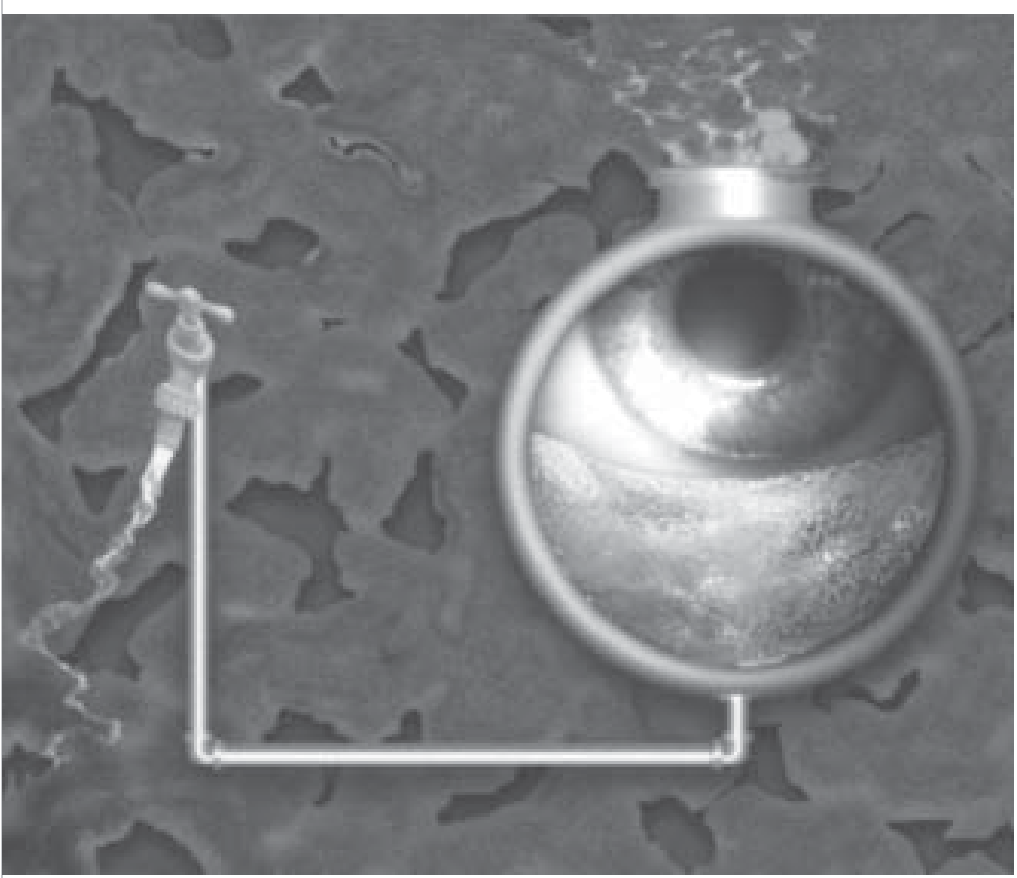




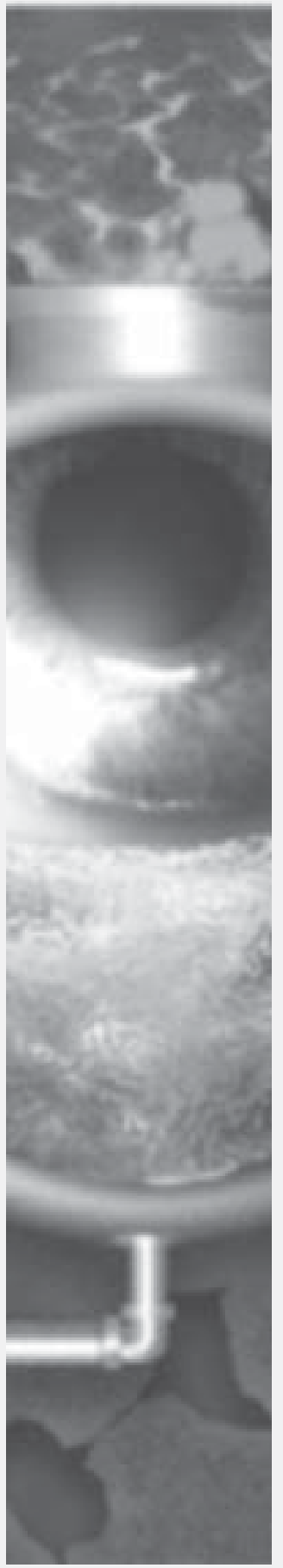

Resumo: Embora a Psicologia organizacional e do trabalho seja a segunda área de escolha de exercício profissional, os cursos de Psicologia, na sua maioria, ainda não a contemplam em toda a sua complexidade e dinâmica de transformação. Com isso, fortalecem-se esquemas cognitivos que representam esse campo de atuação profissional de forma limitada. $\mathrm{O}$ objetivo deste estudo foi o de caracterizar a imagem da Psicologia organizacional entre os estudantes de Psicologia e avaliar o impacto de uma experiência acadêmica sobre a mesma. A amostra consistiu de 150 alunos da única disciplina obrigatória do currículo relacionada à área, que responderam a um questionário aberto na primeira e na última semana do curso, no qual se pedia que escrevessem, espontaneamente, os conceitos e idéias que a área Ihes evocava. Os resultados revelam alterações significativas na imagem, no início e no final do curso. Além de uma visão ampliada, os conteúdos evocados se tornaram mais positivos ao final do curso. Esses resultados apontam mudanças nos esquemas cognitivos dos estudantes, congruentes com as características e a filosofia que estruturavam a disciplina.

Palavras-chave: imagem da Psicologia, Psicologia organizacional, mapas cognitivos.

Abstract: Despite of the fact that organizational Psychology is the second area chosen by Psychology students to work professionally, most of the Psychology courses aren't aware of its complexity and its transformation. Consequently, cognitive schemes that represent this professional field in a limited way grow stronger. This study intended to characterize the image of organizational Psychology among students of the UFBA and evaluate the impact of teaching experience on this image. The sample was formed by 150 students of the only compulsory discipline at the time related to the organizational field. Questionnaires were used at the first and the last week of the term, in which the students were asked to write spontaneously about the concepts and ideas evocated by this field. The results show important transformations of the students' image as evocations became more positive at the end of the course. These results point out changes at the students ' cognitive schemes, congruent with the lines of direction that structured the subject.

Key words: image of Psychology, organizational Psychology, cognitive maps. 
O cenário atual do mundo do trabalho temse caracterizado por alterações de tal magnitude que implicam reestruturação de suas múltiplas facetas, inclusive o papel e expectativas de desempenho dos profissionais envolvidos com a gestão de pessoas. Os avanços tecnológicos e novos modelos de gestão, entre outros fatores complexos, recolocam em posição de destaque a preocupação com a requalificação dos trabalhadores, em todos os níveis e espaços. O psicólogo, como agente e participante desse processo, ao mesmo tempo em que atua profissionalmente lidando com tais transições nas organizações, deve transformarse e buscar competências novas que o habilitem a agir de forma efetiva nesse novo cenário.

O presente trabalho relata as transformações ocorridas na representação do que significa ser psicólogo organizacional em uma amostra de alunos de um curso de graduação, tendo como pano de fundo a reestruturação da disciplina, para oferecer uma visão ampliada das possibilidades e desafios que cercam a atuação desse profissional. O pressuposto assumido no presente trabalho é que, ao longo do processo de formação, o psicólogo desenvolve esquemas cognitivos sobre a sua atuação profissional e tais esquemas guiam as suas decisões e escolhas sobre o que e como atuar. Assim, transformações necessárias ao modelo de atuação serão incrementadas na medida em que as agências formadoras atualizem os esquemas que desenvolvem nos seus formandos.

Como base para a compreensão das decisões metodológicas e dos resultados aqui relatados, a título de introdução, discutimos a formação e atuação profissional do psicólogo organizacional e os fundamentos de cognição social subjacentes ao pressuposto acima explicitado.
Embora não seja a área mais fortemente identificada com o núcleo que define a identidade da Psicologia para alunos e para o público em geral, a atuação do psicólogo organizacional sempre foi expressiva, ocupando, tanto nos levantamentos nacionais como regionais, o segundo lugar em termos de psicólogos dedicados. Faltam, certamente, dados abrangentes e atuais que caracterizem a atuação do psicólogo brasileiro após mais de uma década em que se verificam importantes transformações na forma de se conceber a sua formação e atuação profissional.

Mesmo valendo-se de dados pouco atualizados (CFP, 1988), sabe-se que a busca pela Psicologia organizacional, entre os psicólogos, se deve, em proporção expressivamente superior à observada em outras áreas, a fatores extrínsecos, tais como remuneração ou mesmo falta de opção em outros domínios de atuação do psicólogo. Esse fato gera uma dinâmica ocupacional particular: elevado índice de abandono da área, menor identificação com as tarefas desempenhadas, conciliação de atividades na área com atividades em outras, entre diversas características.

As deficiências na análise dos aspectos conjunturais mais amplos, dos processos macro-organizacionais e a falta da noção de multicausalidade parecem contribuir, decisivamente, para a ineficiência do psicólogo quando se depara com esse contexto de atuação. É comum a adesão a modismos, muitas vezes importados, sem a necessária reflexão acerca da sua pertinência e aplicabilidade aos contextos nacionais. Esses elementos negativos parecem contribuir para a visão estereotipada que as pessoas e os próprios psicólogos possuem em relação à área. A crítica que o psicólogo organizacional seria um mero intermediário das relações de exploração e discriminação do trabalhador pode, em parte, contribuir para os julgamentos negativos concernentes à área. 
Há, contudo, indicadores de inovações ocorrendo na atuação do psicólogo organizacional. Tais inovações foram discutidas amplamente em dois textos do início dos anos noventa (Bastos, 1992; Zanelli, 1994). Suas conclusões ainda hoje parecem válidas para descrever os rumos da área. Práticas tradicionais foram modernizadas, novas práticas surgiram e, sobretudo, passou-se a reconhecer, cada vez mais, a necessidade de o psicólogo lidar com os fenômenos crescentemente complexos do mundo do trabalho e das organizações. O crescimento e consolidação da pesquisa e a intervenção frente aos problemas de saúde ocupacional são marcos distintivos dessa transformação. A inserção em nível mais estratégico (Goulart,1998), a ampliação dos vínculos com outros profissionais em equipes de trabalho, a crescente inserção como consultores e assessores, o desafio de lidar com as mudanças que estão configurando novas organizações, novos padrões de gestão com todas as tensões daí decorrentes (Azevedo e Botomé, 2001), são outras vertentes visíveis de transformação na prática atual do psicólogo organizacional e do trabalho. Essas e tantas outras mudanças nas suas atividades requerem, por seu lado, um novo perfil de profissional, com novas competências que o habilitem a não reproduzir modelos gerados em outros contextos ou pouco sintonizados com o momento atual das organizações.

A área dá importantes sinais de que se está consolidando no País. São indicadores importantes desse processo: a) a criação de uma sociedade científica específica. A Sociedade Brasileira de Psicologia Organizacional e do Trabalho - SBPOT, criada em 2001, tem expandido o número de sócios e já realizou, em 2004, o seu primeiro congresso nacional, com significativo êxito de participação; b) o surgimento do primeiro periódico científico. A revista Psicologia:
Organizações e Trabalho - RPOT, com periodicidade semestral, encontra-se no seu volume 4 e vem-se constituindo em um veículo importante para a divulgação de pesquisas na área; finalmente, um terceiro indicador possivelmente terá importante impacto sobre a própria formação do psicólogo organizacional. Trata-se da publicação Psicologia, Organizações e Trabalho no Brasil, organizada por J. C. Zanelli, J. E. BorgesAndrade e A. V. B. Bastos, o primeiro manual abrangente para ser usado como livro texto em disciplinas da área, construído por um amplo grupo de pesquisadores de várias instituições brasileiras.

As transformações, no entanto, ainda estão distantes, em velocidade e profundidade, daquilo que a produção científica e a reflexão profissional já acumularam ao longo de todo esse período. Segundo Zanelli (1994), as poucas mudanças de foco na área devem-se muito mais aos fatores externos à prática do psicólogo, ou mesmo da administração de recursos humanos, do que às propostas ou intenções dos profissionais da área.

Que fatores podem estar retardando esse processo e impedindo que o psicólogo que atua na área possa vir a cumprir um papel mais significativo e sintonizado com as transformações em curso no mundo do trabalho? Não se pode, para responder a tal questão, deixar de se considerar o papel das agências formadoras, quase sempre reprodutoras de modelos de atuação restritivos e limitados, sobretudo no tocante aos desafios postos pelas organizações de trabalho.

A Psicologia organizacional e do trabalho ocupa, ainda, um lugar reduzido nos cursos de graduação de Psicologia no Brasil. Os currículos, mesmo com as modificações atuais - redefinição das diretrizes curriculares privilegiam ainda a área clínica, mostrando-se
As transformações, no entanto, ainda estão distantes, em velocidade e profundidade, daquilo que a produção científica e a reflexão profissional já acumularam ao longo de todo esse período. 


\section{Entender imagens, idéias, \\ representações e conceitos que as pessoas constroem a respeito de fatos, eventos e partes do seu ambiente nos remete, claramente, para o amplo domínio dos estudos cognitivos e, mais precisamente, para o campo da cognição social.}

1 Apenas como um exemplo, na última avaliação nacional de cursos, em 2003, dos 40 itens fechados, $3 \mathrm{se}$ relacionam à área POT. Um indaga sobre entrevista de seleção; o segundo, sobre modelo de avaliação de desempenho; ambos os itens reportam-se ao núcleo mais tradicional de atividades e o fazem sem exigir qualquer competência mais complexa do formando. $O$ terceiro item toma o filme de Chaplin, Tempos Modernos, para questionar algo que não requer qualquer conhecimento de POT para ser respondido de forma adequada. congruentes com a imagem socialmente mais difundida de atuação do psicólogo, fator que leva à intensa procura por essa formação. Um indicador do reduzido peso ainda atribuído a esse domínio da Psicologia na formação do psicólogo é o exame dos itens utilizados no exame nacional de cursos, o provão, para aferir a qualidade da formação do psicólogo. Segundo a análise das últimas avaliações de Psicologia, pode-se afirmar que a área organizacional ainda é insignificantemente contemplada, e os poucos itens a ela relacionados tratam de conteúdos superficiais e limitados, o que ainda expressa uma concepção de atuação superada no tempo ${ }^{1}$.

Além de insuficientemente contemplada, o processo de formação na área reduz a capacitação do profissional para compreender a complexidade dos ambientes organizacionais atuais, sobretudo ao refletir o modelo do profissional tecnicista com pouca influência nos processos decisórios (Zanelli, 1994). Esse modelo de formação contribui para a constituição de uma imagem distorcida e de expectativas negativas em relação à futura atuação profissional dos estudantes. Tem-se, assim, a junção de dois fatores potencialmente nocivos às transformações que se fazem indispensáveis à atuação do psicólogo na área de organizações e trabalho: espaço insuficiente no curso e visão limitada e distorcida das potencialidades da área nas disciplinas oferecidas.

Como conseqüência, fortalece-se, entre os próprios formandos, uma imagem da área pouco propícia a despertar o interesse e a conduzir ao desenvolvimento profissional dos que a buscam como área potencial de atuação. Como se sabe, a percepção dos psicólogos sobre a área é construída pela experiência da formação acadêmica, por seu contato com o mercado e com os fatores envolvidos na prática cotidiana nas organizações. Atuar sobre os processos que configuram a construção das representações sobre o que significa ser psicólogo organizacional reveste-se de função estratégica para as transformações necessárias a esse domínio de atuação do psicólogo.

Entender imagens, idéias, representações e conceitos que as pessoas constroem a respeito de fatos, eventos e partes do seu ambiente nos remete, claramente, para o amplo domínio dos estudos cognitivos e, mais precisamente, para o campo da cognição social. A perspectiva da cognição social trabalha no "nível da representação" e dá centralidade à natureza social da construção do significado e ao papel da linguagem nesse processo (Bastos, 2001). Como nos afirma Garcia-Marques (2000), os estudos de cognição social pretendem caracterizar o modo como as pessoas processam informações partilhadas socialmente. No contato com a realidade social, construímos nossa percepção sobre nós mesmos e sobre os outros e construímos categorias para tornar mais ágil e fácil o processamento das informações. Essas informações, contudo, não se encontram dispersas e desorganizadas; pelo contrário, elas são organizadas em estruturas cognitivas.

Em uma abrangente revisão de literatura sobre cognição social, Markus e Zajonc (1985) concluem que a teoria de esquemas é a mais proveitosa e penetrante perspectiva sobre os mecanismos da cognição social. Esquemas consistem em uma estrutura organizada de conhecimentos acerca de pessoas, assuntos, objetos que auxiliam os indivíduos no processamento e seleção de informações recebidas do contexto social (Fiske e Taylor, 1991; Augoustines e Walker, 1995; Rodrigues, Assmar e Jablonski, 2000). Assim, eles tomam a forma de expectativas gerais aprendidas através da experiência e da socialização. A partir da formação de esquemas, as pessoas podem compreender seu mundo social e 
estabelecer relações com outros membros desse contexto. Como afirmam Fiske e Taylor (1991), esquemas e categorias nos permitem uma confortável sensação de que compreendemos o nosso mundo. No nosso cotidiano, os esquemas sociais viabilizam as nossas interpretações e percepções de situações e informações. O conceito de esquema enfatiza, portanto, a construção ativa da realidade; os esquemas guiam a percepção, a memória e os julgamentos pessoais.

De campo correlato, embora oriunda de uma tradição de pesquisa distinta, a noção de representação social afigura-se útil para a compreensão da natureza dos resultados obtidos no presente estudo. As representações sociais são estoques de informações e conhecimentos comuns que as pessoas compartilham na forma de teorias do senso comum sobre o mundo social, e é através delas que os membros de uma sociedade são capazes de construir a realidade social. São sistemas cognitivos com uma lógica e linguagens próprias. Elas abrangem desde estruturas hegemônicas, que são compartilhadas homogeneamente pela sociedade, até estruturas de conhecimentos diferenciadas, que são compartilhadas por subgrupos dentro de uma coletividade.

As representações possuem plasticidade e são caracterizadas por serem estruturas de natureza dinâmica. "Uma vez criadas, as representações se comportam como "entidades autônomas" ou "forças materiais" que medeiam e determinam a atividade cognitiva, tendo o propósito de dar ao não familiar uma substância familiar. Os indivíduos são motivados a dar "sentido ao não familiar, atribuindo-lhe significado, sendo que o papel das representações é orientar esse processo" (Augoustininos e Innes, 1990). Nesse amplo e diversificado campo de conhecimento, é de interesse, neste momento, a abordagem estrutural desenvolvida por Abric (1994) e
Moliner (1995), que visa não só a identificar a natureza das representações mas também a buscar a sua centralidade, ou seja, o que, para o caso, haveria de mais importante, o que é essencial. A idéia básica é a de que toda representação está organizada em torno de um núcleo central, que determina, ao mesmo tempo, sua significação e sua organização interna (Abric, 1994).

Finalmente, uma terceira vertente de estudos que toma o conceito de mapa cognitivo se revela importante para o presente trabalho. Quando os alunos fazem evocações a respeito do que, para eles, significa a Psicologia organizacional, acabam representando a imagem da área ao expor os esquemas mentais que determinam as suas atitudes e, em certa medida, "justificam" seus comportamentos relacionados a suas crenças. Por isso, as evocações não são simplesmente opiniões, mas configuram-se como partes importantes do comportamento dos sujeitos.

Os mapas cognitivos, além de um conceito que se reporta a uma estrutura cognitiva (como idéias, conhecimento, conceitos, organizados mentalmente), consistem em uma estratégia metodológica utilizada para representar essas cognições e crenças. Esse modelo de representar está especialmente voltado para explicitar os processos de construção de sentido e a estruturação do conhecimento ("schemas") tanto entre indivíduos como entre grupos e organizações (Bastos, 2002). Os mapas seriam, segundo Laukkanen (1992), uma das ferramentas alternativas para representar dados (respostas orais e expressões escritas que expressam afirmações, predições, explanações, argumentos, regras e dicas não verbais) através dos quais temos acesso a representações internas e a elementos cognitivos (imagens, conceitos, crenças causais, teorias, heurísticas, regras, scripts, etc). 
A diversidade de mapas, em parte, resulta das múltiplas relações possiveis a serem estabelecidas entre os conceitos ou elementos cognitivos.
A diversidade de mapas, em parte, resulta das múltiplas relações possíveis a serem estabelecidas entre os conceitos ou elementos cognitivos. Como destacam Bougon (1983) e Huff (1990), essas relações podem ser: de associação ( $A$ me lembra $B$ ), de grau de similaridade (A e B são diferentes), do valor relativo (A é mais importante que $B$ ), do vínculo causal (A causa B), de argumentação (se A é verdade, então B não é verdadeiro). Os mapas podem, também, fazer inferências sobre o sujeito a partir da sua fala (se A e B são mencionados, então há a influência de $\mathrm{C}$ ). O mapeamento cognitivo lida, preferencialmente, com relatos verbais ou discursos e busca preservar, ao máximo, a linguagem dos participantes. Portanto, pode ser inserido no grupo de estratégias de pesquisa qualitativas e intensivas, apesar de algumas técnicas permitirem e trabalharem indicadores quantitativos a partir do material qualitativo coletado inicialmente.

Bastos (2002), ao avaliar as contribuições dessa ferramenta metodológica, destaca o envolvimento dos sujeitos com o processo de construção dos mapas, permitindo uma reflexão sobre a própria visão deles. Outros pontos relevantes referem-se à coleta de dados menos diretiva, preservação da linguagem natural, importância do processo de análise do conteúdo e criação das categorias que estruturam os mapas.

Ao se investigarem as representações ou a imagem que o estudante de Psicologia possui sobre a Psicologia organizacional, utilizando esse método, poder-se-ia ter um acesso privilegiado ao que existe de central - sem, necessariamente, ser comum ou consensual - entre as diferentes formas de se pensar a formação e a imagem e perfil do aluno bem como as concepções que tangenciariam e se estruturariam em torno desse núcleo. Com isso, pode-se dar um passo importante para compreender as incongruências entre as suas imagens, o paradoxo entre essas imagens, o paradigma dominante na área e também a "penetração" do discurso do senso comum nesse campo.

Colocados tais fundamentos, o presente estudo teve como objetivos específicos: a) avaliar o nível de interesse despertado pelos diversos campos de atuação entre alunos do curso de graduação em Psicologia de uma universidade pública; b) caracterizar a imagem da Psicologia organizacional entre os estudantes, avaliando o impacto da disciplina Psicologia industrial sobre a mesma; c) analisar o conjunto de crenças que dão suporte ao movimento pessoal de afastamento e aproximação dos alunos em relação ao campo da Psicologia organizacional, antes e depois da experiência de terem cursado a disciplina específica da área, a única existente no currículo do curso, no momento da coleta de dados.

\section{Método}

O estudo foi conduzido com o objetivo de avaliar as mudanças introduzidas no âmbito de uma disciplina obrigatória do curso de graduação de Psicologia, em uma etapa anterior à ampla reforma curricular implementada no curso. A disciplina, reestruturada, mas ainda mantendo um rótulo antigo e consagrado no currículo mínimo do curso, pautou-se pelo princípio de oferecer uma visão ampliada da Psicologia organizacional como campo de investigação e atuação profissional. Em um primeiro módulo, ofereciase uma visão de múltiplas visões da organização, nos seus processos macro e microorganizacionais. Em um segundo módulo, oferecia-se uma visão panorâmica dos diversos conjuntos de atividades desenvolvidas pelo psicólogo em equipes multiprofissionais, com ênfase nas transformações que vinham 
ocorrendo em todas essas atividades. A experiência acadêmica foi estruturada com base em uma concepção que define a área de Psicologia organizacional e do trabalho como apoiada em um tripé que corresponde aos seus principais objetos de estudo e intervenção - a organização, o trabalho e os processos de gestão. Assim, constitui-se como um domínio que faz interfaces com vários outros campos do saber, o que é fonte de diversidade teórica, metodológica e tecnológica.

A amostra consistiu de 150 alunos da disciplina Psicologia industrial, na Universidade Federal da Bahia, que responderam a um questionário na primeira e na última semana do curso. O instrumento continha duas questões abertas e uma fechada. Na primeira questão aberta, pedia-se que os estudantes escrevessem, espontaneamente, os conceitos e idéias que a Psicologia organizacional lhes evocava. $\mathrm{Na}$ segunda, que enumerassem os motivos que os afastavam e os que os aproximavam da Psicologia organizacional, e, na questão fechada, pedia-se que os estudantes distribuíssem 100 pontos entre as cinco áreas de atuação preferidas (clínica, escolar, organizacional, comunitária e ensino). Os dados foram coletados na própria sala de aula. O processo de análise do conteúdo envolveu a criação de categorias descritivas das evocações espontâneas obtidas através das questões abertas. As respostas das questões foram agrupadas e categorizadas com base no seu conteúdo, definindo-se categorias e suas freqüências de aparecimento no grupo; adicionalmente, observou-se a ordem de evocação de cada idéia, segunda dimensão utilizada para a construção dos mapas cognitivos que, no presente estudo, articulam a teoria do núcleo central das representações (Abric, 1994; Moliner, 1995) e as idéias de esquemas e mapas cognitivos (Bougon, 1983).
As categorias que tiveram maior freqüência e maior força de evocação formaram o núcleo central da imagem da área. Esses mapas (antes e depois do curso) representam a forma pela qual os estudantes estruturaram suas percepções frente à Psicologia organizacional nos dois momentos, e as diferenças entre eles constituem a base para a avaliação do impacto da disciplina.

Os dados obtidos depois da categorização foram inseridos em um banco de dados no SPSS, no qual foram realizados os cálculos das freqüências e ordem de evocação de cada categoria, assim como retiradas as médias de escolha de cada área de atuação. Obtidas a freqüência e a ordem de evocação de cada categoria, foram construídos os mapas cognitivos dos alunos, antes e depois do curso. Para facilitar a compreensão e melhorar as representações gráficas dos mapas, as categorias, nas duas dimensões, foram ordenadas do primeiro ao último posto. Por exemplo: se uma categoria teve a maior freqüência, ela recebeu a primeira classificação (correspondente a 25), e, se ela teve a melhor ordem de evocação, também recebeu a primeira classificação (correspondente a 25). Assim, quanto maior a ordem e a freqüência na representação gráfica, maior é a força ou importância da categoria no grupo. Cada um desses mapas está estruturado em quatro quadrantes. No $1^{\circ}$ quadrante, estão as idéias mais centrais (maior freqüência de citação e mais prontamente evocadas); no $2^{\circ}$ quadrante, estão as idéias com ordem de evocação elevada, mas com baixa freqüência; no $4^{\circ}$ quadrante, ocorre o inverso: estão as idéias com maior freqüência e menor ordem de evocação, e finalmente, no $3^{\circ}$ quadrante, estão as idéias com ordem de evocação e freqüência baixas.
Para facilitar a compreensão e melhorar as representações gráficas dos mapas, as categorias, nas duas dimensões, foram ordenadas do primeiro ao último posto. 


\section{Resultados}

Como resultado da análise de conteúdo, as evocações livres foram agrupadas em 36 categorias que descrevem a variedade das respostas, conforme se pode ver na Tabela 1.

Tabela 1 - Descrição das categorias dos mapas e o seu valor cognitivo

\begin{tabular}{|c|c|c|}
\hline Nome da categoria & descrição da categoria & valor \\
\hline Complexidade e desafio & $\begin{array}{l}\text { O trabalho nas empresas visto como algo complexo e marcado por dificuldades } \\
\text { e desafios, tendo uma distância entre a teoria e a prática. }\end{array}$ & \multirow{4}{*}{ 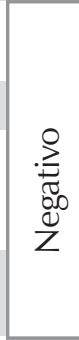 } \\
\hline Limitado pela estrutura burocrática & Trabalho limitado e pouco autônomo, com imposições por parte da empresa & \\
\hline Poder e política & $\begin{array}{l}\text { (burocratização, trabalho mecânico e limitado). } \\
\text { O ambiente das empresas é marcado por disputas de poder, conflitos e política, } \\
\text { constituindo-se num ambiente negativo e autoritário. }\end{array}$ & \\
\hline Subordinado aos interesses do capital & $\begin{array}{l}\text { O psicólogo exerce uma função de subordinação à política capitalista e faz um trabalho } \\
\text { de adaptação do funcionário aos interesses da empresa (capitalismo, doutrinação e lobo mau). }\end{array}$ & \\
\hline Administração & $\begin{array}{l}\text { Engloba conceitos referentes diretamente à administração em diversos níveis } \\
\text { (administração científica, participativa e sistemática). }\end{array}$ & \multirow{15}{*}{ 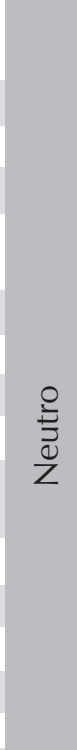 } \\
\hline Análise do trabalho & Basicamente, análise de cargos e de funções. & \\
\hline Análise institucional & Condições que o campo oferece para desenvolver trabalhos de análiseinstitucional . & \\
\hline Avaliação / diagnóstico & Envolve diagnóstico organizacional e avaliação de grupos e de processos. & \\
\hline Campo de pesquisa & $\begin{array}{l}\text { As possibilidades e linhas de pesquisa na área; o psicólogo pode atuar também } \\
\text { como pesquisador. }\end{array}$ & \\
\hline Contextos organizacionais & Conceitos bastante concretos, tais como fábrica, empresa, organizações. & \\
\hline Cultura / clima & Basicamente, conceitos referentes a clima e cultura organizacional. & \\
\hline Desconhecimento & O desconhecimento em relação à área. & \\
\hline Desenho de cargos & Envolve conceitos relativos a desenho de cargos. & \\
\hline Intervenção macro & $\begin{array}{l}\text { Diz respeito às funções do psicólogo num plano mais gerencial, tais como gerência de RH, } \\
\text { elaboração de proj. de intervenção, consultoria. }\end{array}$ & \\
\hline Motivação/satisfação & Basicamente, motivação e satisfação com o trabalho. & \\
\hline Liderança & Liderança e estilos de liderança. & \\
\hline Produtividade/desempenho & Engloba conceitos relativos a competitividade, proficiência e desempenho. & \\
\hline Recrutamento & Refere-se exclusivamente ao recrutamento de pessoal. & \\
\hline Seleção de pessoal & Refere-se exclusivamente à seleção de pessoal. & \\
\hline Técnicas de intervenções clássicas & Engloba a aplicação e avaliação de testes e a realização de entrevistas. & \\
\hline Conciliação empresa-empregado & $\begin{array}{l}\text { Visão do psicólogo como conciliador dos interesses dos trabalhadores e da } \\
\text { empresa, promovendo maior bem-estar e produtividade para ambas a partes. }\end{array}$ & \multirow{11}{*}{ 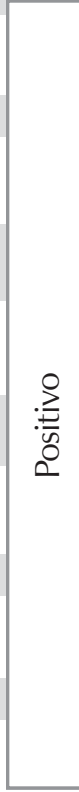 } \\
\hline Expansão / visibilidade & A área organizacional está em expansão e tem boas possibilidades deatuação. & \\
\hline Grupos/ dinâmicas de grupo & $\begin{array}{l}\text { Conceitos ligados a dinâmicas de grupos e facilitação das relações } \\
\text { interpessoais. }\end{array}$ & \\
\hline Imagem organizacional / sistêmica & $\begin{array}{l}\text { Visão das organizações dentro de uma perspectiva sistêmica, orgânica, baseada sobretudo } \\
\text { nas metáforas propostas por Morgan para compreender o funcionamento das organizações. }\end{array}$ & \\
\hline Multidisciplinaridade & $\begin{array}{l}\text { Noção do psicólogo como alguém que necessita de uma visão mais global, multidisciplinar } \\
\text { e de atuação em equipe. }\end{array}$ & \\
\hline Nova visão pessoal & $\begin{array}{l}\text { Idéias relativas a um novo modo de pensar com relação à Psicologia } \\
\text { organizacional após o curso. }\end{array}$ & \\
\hline Perspectivas sociais & $\begin{array}{l}\text { Imagem de uma psicologia voltada para o campo social, interessada sobretudo em processos } \\
\text { sociais. }\end{array}$ & \\
\hline Programas de mudanças & Programas de qualidade total, controle de qualidade e reengenharia. & \\
\hline Saúde e QVT & $\begin{array}{l}\text { Envolve conceitos referentes tanto à promoção da qualidade de vida no } \\
\text { trabalho quanto às condições adoecedoras. }\end{array}$ & \\
\hline Treinamento e desenvolvimento & Refere-se, de modo geral, ao crescimento e aperfeiçoamento do trabalhador. & \\
\hline Vínculo indivíduo-trabalho & $\begin{array}{l}\text { Engloba conceitos ligados ao envolvimento, comprometimento e significado } \\
\text { do trabalho na vida do trabalhador. }\end{array}$ & \\
\hline
\end{tabular}


As categorias descritas na Tabela 1 foram, adicionalmente, agrupadas em três segmentos, conforme o caráter avaliativo subjacente a cada evocação. Categorias com idéias negativas sobre a área sinalizavam limites e restrições de diversas ordens, a exemplo da subordinação do psicólogo aos interesses do capital, os limites impostos pela burocracia e as questões de poder e conflito imbricadas na atividade profissional. Categorias associadas a uma avaliação positiva, ao contrário, assinalavam aspectos que tornam essa área relevante e em expansão, quer por lidar com questões sociais quer por assinalar conjunto de atividades que traziam uma visão ampliada e nova desse domínio (por exemplo, um campo multidisciplinar, programas de mudança, atuação na saúde e qualidade de vida etc.). Também foram incluídas, como categorias positivas, expressões de mudanças pessoais na forma de ver essa área. Finalmente, há um conjunto maior de categorias frente às quais não se pode perceber uma clara localização do seu conteúdo na dimensão avaliativa, quer positiva, quer negativa. São conteúdos descritivos das diversas atividades e conceitos que estruturam a Psicologia organizacional como campo de conhecimento e de intervenção. A figura 01 mostra o mapa cognitivo dos alunos no momento inicial do curso.

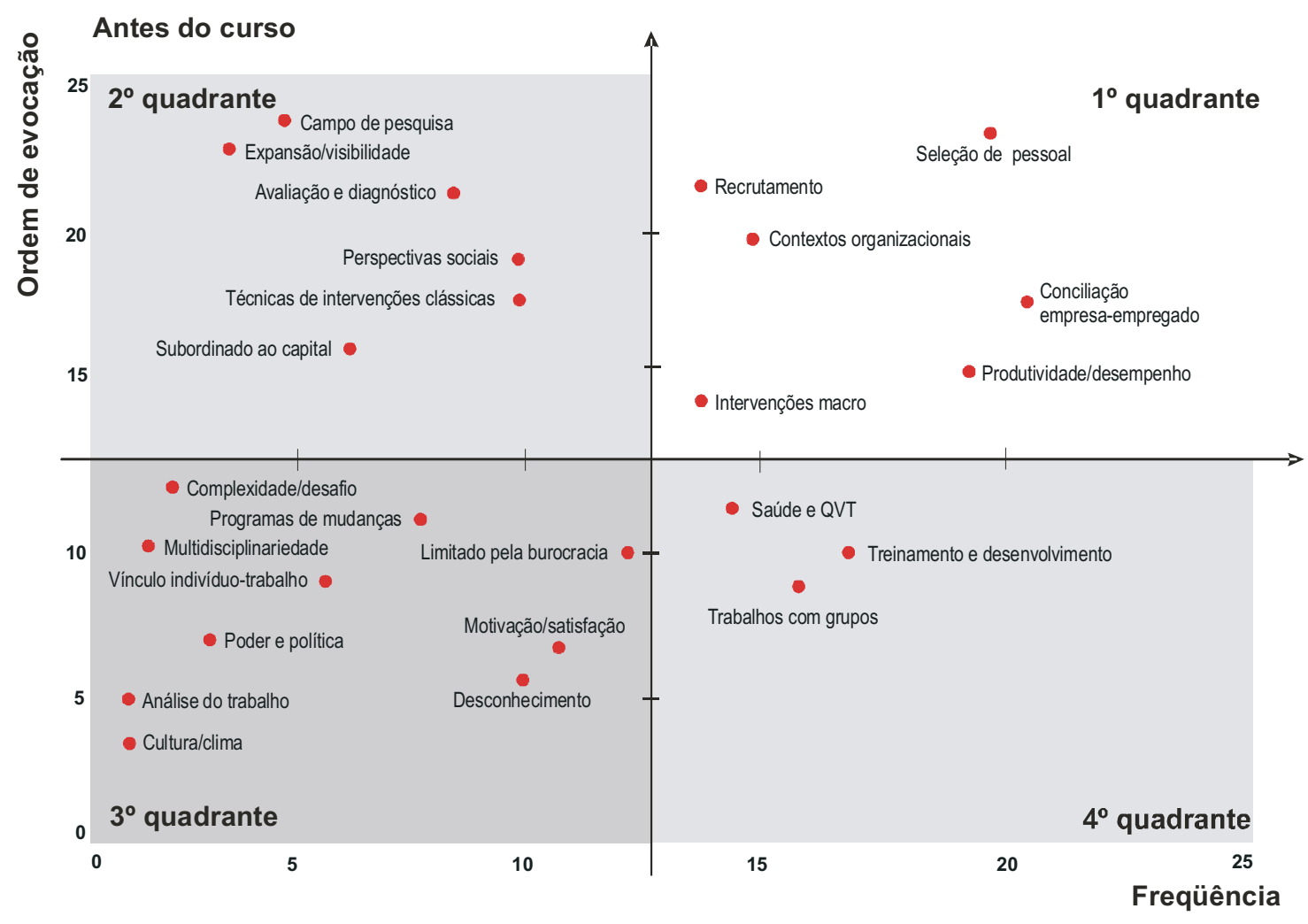

Figura 1 - Mapa cognitivo no início do curso.

O mapa cognitivo do grupo, no início do curso, mostra que as idéias mais fortes ou o núcleo central ( 1 - quadrante) se estruturam em torno de idéias como "seleção de pessoal", "recrutamento", "contextos organizacionais", "conciliação empresa/empregado", "produtividade/desempenho" e "intervenções macro". Não é difícil perceber que estamos diante de uma representação bastante tradicional da área e que corresponde à sua imagem socialmente mais difundida, ou seja, representa o modelo dominante de atuação do psicólogo em contextos organizacionais. Outro dado interessante é o de que, à exceção 
da categoria "conciliação empresa-empregado", todos os conteúdos desse quadrante são neutros, não implicando uma clara valoração do significado para o grupo.

Por outro lado, quando olhamos as idéias mais fracas - com pior ordem de evocação e menor freqüência - apresentadas no 3o quadrante, aparecem conteúdos como: "cultura/clima", "análise do trabalho" e "desconhecimento", "motivação/satisfação", "limitado pela burocracia", "poder e política", "vínculo indivíduo-trabalho", "multidisciplinaridade", "programas de mudanças" e "complexidade". Há uma mescla de elementos positivos, negativos e neutros que, perifericamente, definem a imagem da área para o conjunto de alunos.

O mapa cognitivo no início do curso contrasta com o mapa que apresenta as idéias dos estudantes no momento final do curso. Esse mapa, que pode ser visto na figura 02, mostra as evocações dos alunos após as atividades (teóricas e práticas) desenvolvidas na disciplina, ou seja, além dos conteúdos teóricos, os alunos tiveram a oportunidade de realizar um trabalho prático em uma organização, descrevendo-a e avaliando alguns dos seus problemas.

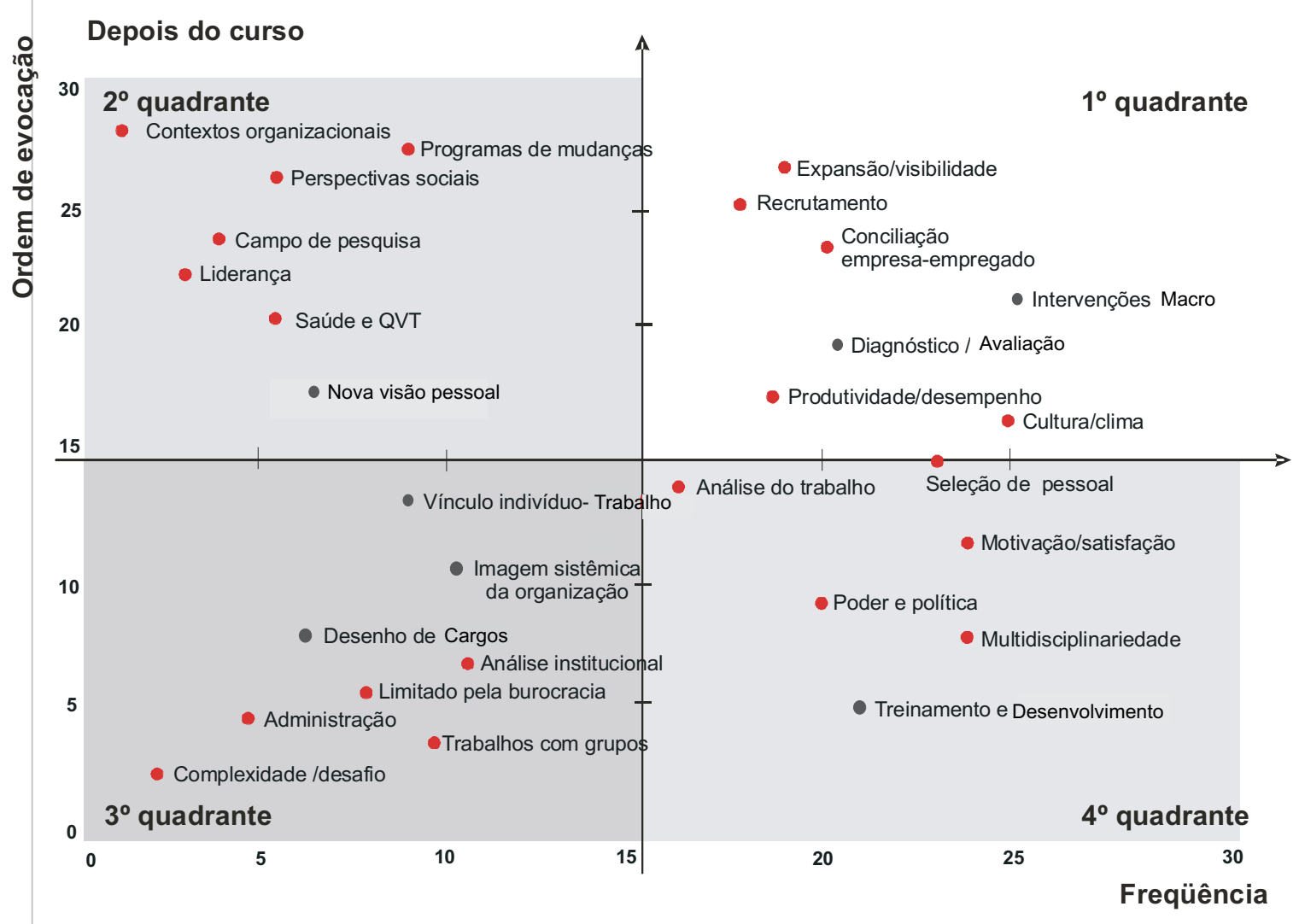

Figura 02 - Mapa cognitivo ao final do curso.

O mapa desse segundo momento mostra que o núcleo central, agora, incorpora três novos conteúdos e estrutura-se em torno de conceitos como "expansão/visibilidade", "diagnóstico e avaliação" (antes no $2^{\circ}$ quadrante), "cultura e clima organizacional" (antes no 30 quadrante). Aqui se destaca, especialmente, a idéia de maior visibilidade e expansão da visão sobre a área como um claro resultado da experiência no curso, além de dois conteúdos fortemente associados às atividades 
teóricas e práticas da disciplina - cultura e diagnóstico organizacionais. Três conteúdos permanecem do primeiro mapa: as de "intervenções macro", "conciliação empresa/empregado", "produtividade/ desempenho" e "recrutamento". Duas idéias, no entanto, deixaram de fazer parte do núcleo central no segundo mapa. A idéia de "seleção de pessoal" foi para o quarto quadrante (alta freqüência e baixa evocação) e "contexto organizacional" foi para o segundo quadrante (menor freqüência e alta evocação).

As idéias com menor força de evocação e freqüência ( $3^{\circ}$ quadrante) depois do curso são: "complexidade/desafio", "trabalhos com grupos", "limitado pela burocracia", "administração", "análise institucional", "desenho de cargos" e "imagem sistêmica", sendo que os quatro últimos constituem evocações inéditas. Essas novas idéias possuem correlação com o conteúdo ministrado no curso. Outras idéias novas surgem, também no segundo quadrante: "liderança" e "nova visão pessoal". É importante chamar a atenção para as idéias "complexidade/desafio" e "limitado pela burocracia", que se mantiveram no $3^{\circ}$ quadrante nos dois mapas, e para a idéia de "trabalhos com grupos", que enfraqueceu e foi do 4 o para o 3 o quadrante. É interessante notar, ainda, que as idéias de "subordinado ao capital" e "desconhecimento" desaparecem no segundo mapa.

Essas transformações, tanto no núcleo central quanto na parte periférica da imagem, revelam a força da experiência acadêmica específica na reconstrução da representação sobre o domínio da Psicologia organizacional e do trabalho. O aparecimento de novas categorias de conteúdo e o deslocamento de categorias similares entre os quatro quadrantes do mapa destacam o papel das agências formadoras como potencializadoras de transformações significativas na forma como o graduando passa a ver o seu futuro campo de trabalho. São pertinentes, portanto, as indicações de Bastos (1992) e Zanelli (1994) quando apontam a formação como reprodutoras de um modelo de atuação limitada para a área da Psicologia organizacional e do trabalho.

Um dado adicional sobre o impacto do curso na representação da área pelos alunos surge da comparação da posição de cada aluno quanto ao valor positivo ou negativo dos conteúdos evocados. Como visto, cada evocação foi analisada quanto à sua natureza avaliativa (neutra, positiva e negativa). Do exame do conjunto de evocação de cada participante, foram criadas categorias que descrevem o peso das avaliações positivas ou negativas, o que pode ser visto na figura 03 , nos dois momentos do curso.

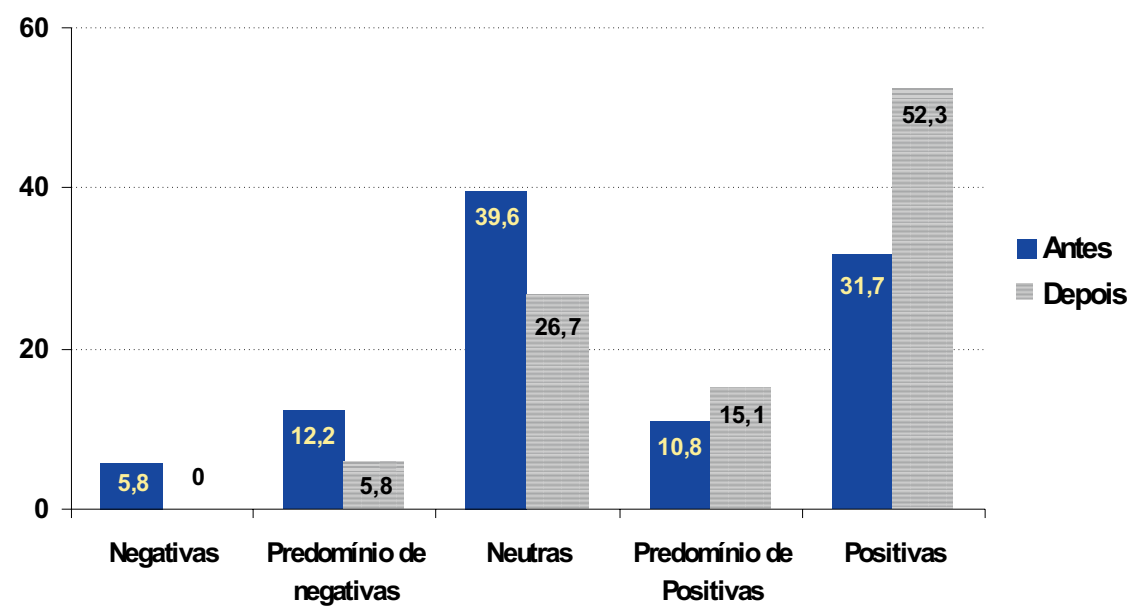

Figura 3 - Natureza das categorias evocadas nos mapas no início e ao final do curso. 
Como facilmente se percebe, houve um claro movimento do grupo em direção a evocarem idéias ou conteúdos que traziam, subjacentes, avaliações mais positivas da área. Cresceu o contingente de alunos que, no seu conjunto, tinham um predomínio de conteúdos positivos (de 10,8 para $15,1 \%$ ). Mais expressivo foi o crescimento do número de alunos que só evocaram idéias positivas (antes representavam 31,7\% e, após o curso, chegam a 52,3\%). De forma simétrica, diminuem aqueles que só evocaram conteúdos neutros ou que evocavam maior número de conteúdos negativos. Após o curso, também, desapareceram os poucos casos que só conseguiram evocar conteúdos com clara avaliação negativa da área.

A última questão investigada estava relacionada aos motivos que aproximam ou afastam os alunos da área organizacional, ou seja, as explicações ou crenças utilizadas para justificar sua proximidade ou afastamento, cujas categorias se encontram nas tabelas 2 e 3.

Nome da categoria

Campo de atuação restrito

Descrédito social da área

Falta de aptidão

Falta de autonomia

Falta de informações sobre a área

Falta de interesse pelo trabalho

Interesse por outras áreas

Limitado aos interesses do capital

Nenhum

Trabalho burocrático

Trabalho tradicional do psicólogo (recrutamento e seleção)

\section{descriçao da categoria}

Campo restrito e limitante no que diz respeito à utilização das habilidades do psicólogo. Descrédito em relação ao trabalho do psicólogo. Falta de aptidão ou interesse pelo trato político e para lidar com relações de poder.

Conceitos ligados à falta de autonomia, pouca influência nos processos decisórios e limitações impostas pela hierarquia.

A falta de informação sobre a área.

Desinteresse pelo trabalho em empresas e pela conseqüente desumanização das relações interpessoais nesses ambientes.

Interesse pela atuação em outras áreas ou por trabalho mais individualizado.

Visão do trabalho do psicólogo como algo limitado aos interesses da empresa e do capitalismo.

Nada que afaste dessa área.

Trabalho do psicólogo visto como algo burocrático, mecânico, monótono e repetitivo.

Conceitos associados às funções tradicionais do psicólogo, como aplicação de testes, recrutamento e seleção de pessoal.

Tabela 2 - Motivos de afastamento da área organizacional 
Tabela 3 - Motivos de aproximação da área organizacional

Nome da categoria
Campo em expansão
Capacidade / interesse
pessoal
Desafios / crescente
ampliação da área

Dimensão social do trabalho

Interesse por maior contato

e aprofundamento

Nova visão decorrente das

experiências do curso

Possibilidade de atuação

humanística

Possibilidade de trabalho

sistemático / produtivo

\section{descrição da categoria}

Campo em expansão, com maior aceitação e perspectivas promissoras de atuação para estagiários, recém-formados e profissionais.

Capacidade e interesse para trabalhar com empresas e administração.

Área desafiante, estimulante, diversificada e em crescente ampliação.

Trabalho com grupos e com ênfase na dimensão social do ser humano.

Interesse em travar maior contato com a área da Psicologia do trabalho.

Visão mais aprofundada e realística da área após ter passado pelo curso de Psicologia.

Atuação visando à valorização do trabalhador e à melhoria das condições de trabalho, tornando-o algo prazeroso.

Área de atuação mais objetiva, sistemática e com resultados visíveis, baseada em dados concretos; maior segurança para intervir.

As vantagens salariais e a possibilidade de estabilidade financeira.

É evidente que o curso não pretendia trabalhar com a hipótese de vir a transformar todos os alunos em futuros psicólogos organizacionais. O importante, no entanto, como se pode observar na figura 4 , é que houve mudança importante nos motivos utilizados para explicar o que afasta o aluno dessa área de atuação. Antes, o desconhecimento era o fator mais importante. Essa explicação apresenta uma forte queda ao final do curso. A área passa a ser menos vista como restrita e "vendida" aos interesses do capital. Conhecendo mais a área, aparecem motivos consistentes com seus interesses reais gostar mais de outras áreas, ter mais aptidão para outro tipo de atuação, querer um trabalho com mais autonomia. Todas essas explicações superam a visão estereotipada da área. 


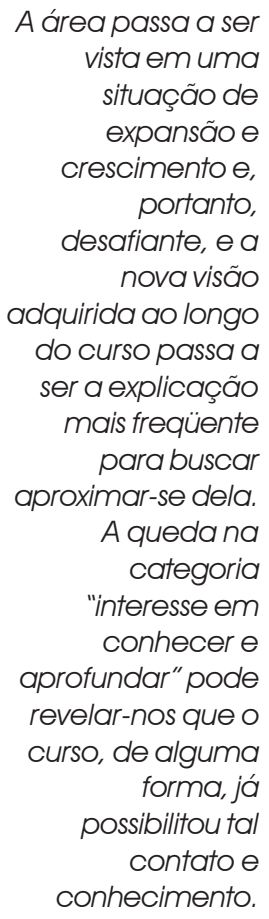

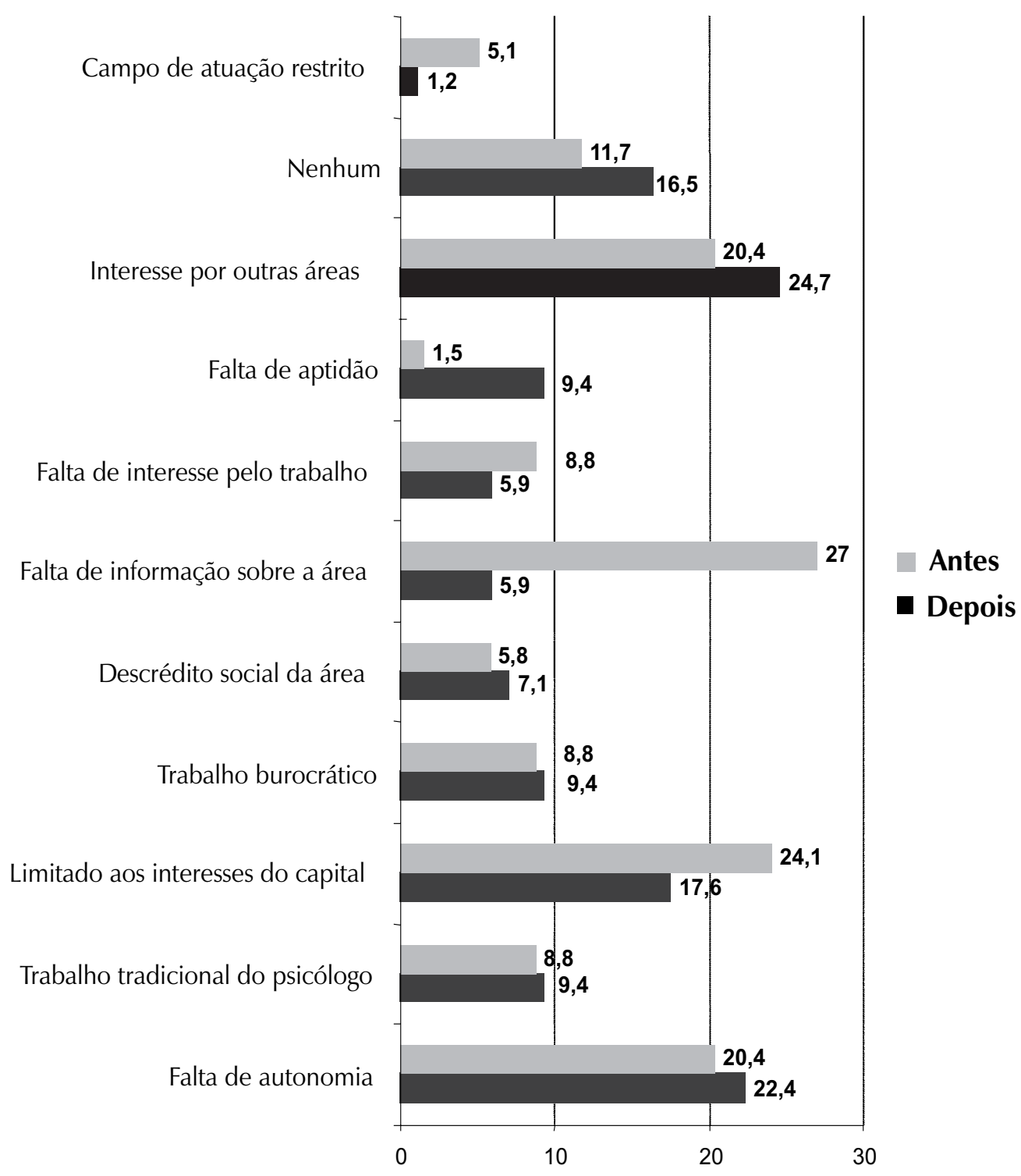

Figura 4 - Motivos que afastam da área organizacional antes e depois do curso.

Embora não elimine restrições à área, o curso parece ter despertado uma nova visão sobre a mesma. Isso é o que se depreende das respostas aos motivos que explicam a aproximação da área organizacional, dados que podem ser vistos na figura 05. A área passa a ser vista em uma situação de expansão e crescimento e, portanto, desafiante, e a nova visão adquirida ao longo do curso passa a ser a explicação mais freqüente para buscar aproximar-se dela. A queda na categoria "interesse em conhecer e aprofundar" pode revelar-nos que o curso, de alguma forma, já possibilitou tal contato e conhecimento. 


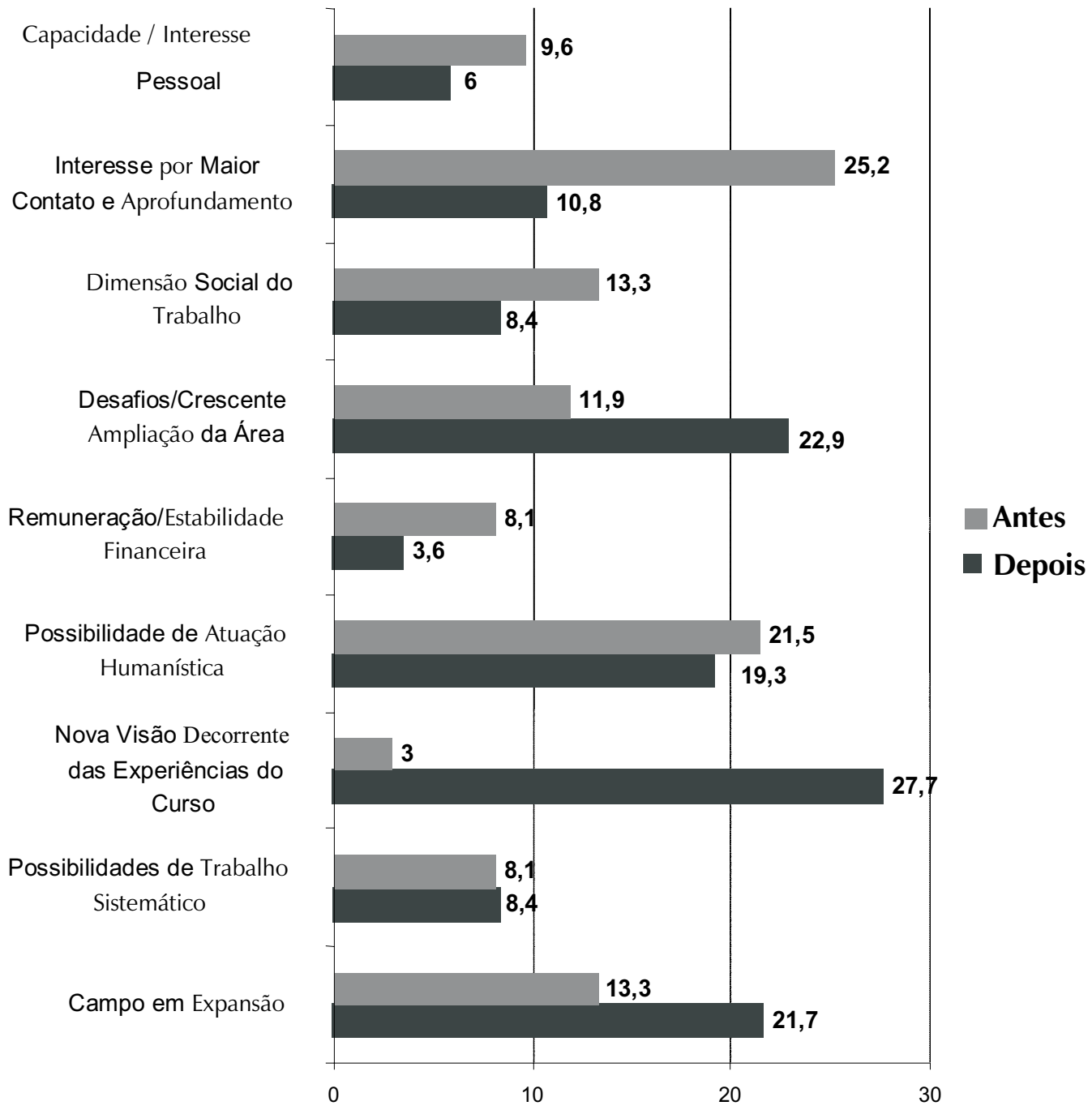

Figura 5 - Motivos que aproximam da área organizacional antes e depois do curso.

Adicionalmente, vale registrar que, entre o momento inicial e final do curso, constatou-se uma diminuição no quantitativo de motivos que afastam e crescimento do número de motivos que aproximam o estudante da área. Esse dado é congruente, também, com o maior peso que a área organizacional recebeu na avaliação comparativa com as demais áreas².

Em síntese, os dados revelam que, antes da experiência da disciplina, a falta de informações é o motivo que mais afasta os estudantes. Esse desconhecimento é base para estereótipos e a manutenção de uma visão bastante limitada sobre o que faz o psicólogo organizacional e do trabalho. Esse estereótipo centra-se nas idéias de a área estar fortemente ligada e limitada pelas imposições do capital e da falta de autonomia, o que, de certa forma, contraria o modelo idealizado do psicólogo como profissional liberal, livre das imposições do trabalho burocrático. As principais evocações que sustentam os motivos de aproximação são os "desafios da área em expansão" e "uma nova visão mais realista e informada sobre esse campo de atuação".

2 Na questão em que cada aluno distribuía 100 pontos entre as cinco principais área de atuação do psicólogo, verificou-se um aumento do peso da preferência pela área organizacional (única em que o escore médio cresceu significativamente de 20,86 para 26,18 pontos). 


\section{Conclusões}

O conjunto de dados apresentados nos permite não apenas caracterizar a imagem da área organizacional entre alunos de graduação de Psicologia, mas, sobretudo, avaliar as transformações ocorridas pelo impacto de uma experiência acadêmica concebida, especialmente, com o objetivo de alterar a representação que os alunos possuem dessa importante forma de inserção profissional do psicólogo, no Brasil e no mundo. Pelo fato de ser a única obrigatória do currículo, a disciplina deixava de contemplar uma visão renovada da área e fortalecia, entre os estudantes, o estereótipo dominante sobre o que significava a Psicologia aplicada ao mundo do trabalho. Essa visão restrita e limitada fica explícita no mapa cognitivo traçado no início da experiência.

Os resultados, ao final do curso, contudo, apontam mudanças nos esquemas cognitivos dos estudantes, congruentes com as características e a filosofia que estruturavam a disciplina - o objetivo da disciplina era exatamente atualizar os alunos em conteúdos novos e em tipos consistentes de trabalho no cenário organizacional. O impacto do curso se mostrou no sentido de substituir evocações imprecisas e com tendências negativas, muitas vezes sustentadas por grande falta de informação, por outras mais concretas e com conteúdo mais positivo.

Finalmente, vale ressaltar que a estratégia metodológica utilizada para captar essas transformações nos parece acertada. A evocação espontânea de cognições mostrouse uma estratégia satisfatória para descrever a visão que os estudantes têm da área e que sustenta suas atitudes em relação à mesma. Além disso, a possibilidade de comparar os conteúdos e estrutura dessas evocações antes e depois do curso tornou-se um importante insumo para mostrar qual a mudança de cognição, de crenças e de idéias a respeito da área organizacional após a realização do curso. Essas mudanças podem significar aquisição de conhecimento e ampliação da visão sobre o trabalho que o psicólogo desenvolve no interior das organizações.

As mudanças identificadas entre os dois momentos do levantamento, em cada turma, não podem ser atribuídas, com segurança, à experiência do curso. O delineamento de pesquisa aqui utilizado não controla um conjunto de outros fatores que podem ter afetado as percepções dos alunos sobre a área. Embora sem a segurança de um delineamento perfeito, o estudo reúne um conjunto bastante significativo de evidências que mostram a possibilidade de se produzirem reestruturações importantes na forma como o aluno de graduação percebe os diversos caminhos potenciais de atuação profissional. 


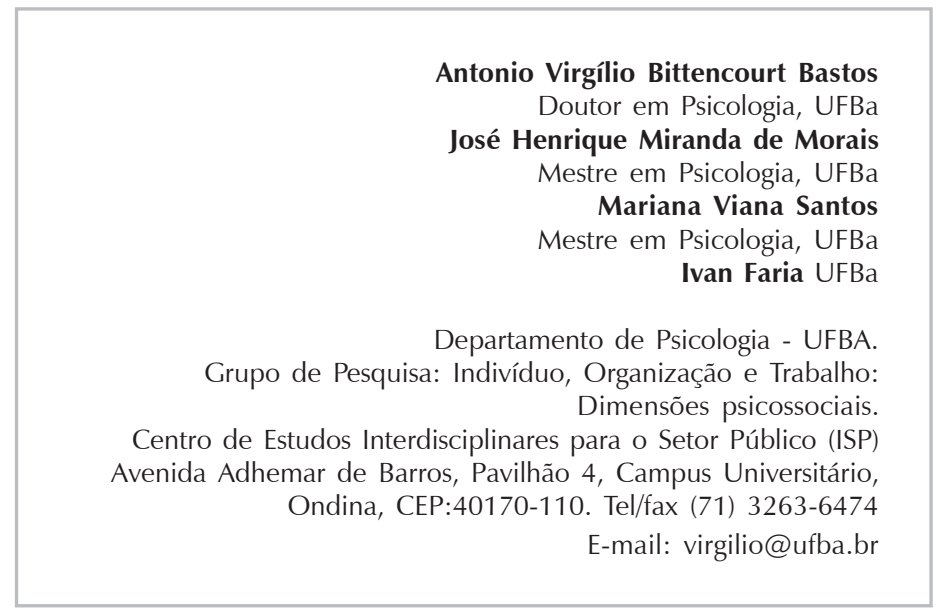

ABRIC, J. C. L'Organisation Interne des Représentations Sociales: Système Central et Système Oeripherique. In Ch. Guimelli. Structures et Transformations des Représentations Sociales. Lausanne: Delachaux et Niestlé, 1994, pp. 73-84.

AUGOUTINOS, M. \& WALKER, I. Social Cognition. Londres: SAGE Publications, 1995.

AUGOUSTINOS, M. \& INNES J. M. Para uma Integração das Representações Sociais e a Teoria do Esquema Social. British Journal of Social Psychology. Londres: 27-1990.

AZEVEDO B. M. E BOTOMÉ S. P. Psicólogo Organizacional Aplicador de Técnicas e Procedimentos ou Agente de Mudanças e de Intervenção nos Processos Decisórios Organizacionais? Revista Psicologia: Organizações e Trabalho, vol. 01, nº 01, jan./jun. de 2001.

BASTOS, A. V. B. \& GOMIDE, P. I. C. (org.). Quem é o Psicólogo. São Paulo: Edicon, 1988.

BASTOS, A. V. B. A Psicologia no Contexto das Organizações: Tendências Inovadoras no Espaço de Atuação do Psicólogo. In Psicólogo Brasileiro: Construção de Novos Espaços. Campinas: Editora Átomo, 1992

. Cognição e Ação nas Organizações. In Davel, E.; Vergara S.C. Gestão com Pessoas e Subjetividade. São Paulo: Editora Atlas, 2001.

Mapas Cognitivos e a Pesquisa Organizacional: Explorando Aspectos Metodológicos. Estudos de Psicologia, vol. 7. Natal : Edufrn, 2002, pp. 65-77.

BOUGON, M. G. Descobrindo Mapas Cognitivos. Técnica de Auto-Questionamento. Pennsylvania: SAGE, 1983.
CAMINO, L., MACIEL, C., BRANDÃO, C. \& Cols. O Conhecimento do Outro: Primeiras Explicações em Termos de Percepção Social. Monografias em Psicologia Social da UFPB. 1, 1996, pp. 13-69.

FISKE, S. T. E TAYLOR, S. E. Social Cognition. New York: McGrawHill, 1991.

GARCIA-MARQUES T. Cognição Social: Contribuições para o Estudo do Comportamento Organizacional. In S.B. Rodrigues e M. Pina. Estudos Organizacionais: Novas Perspectivas na Administração de Empresas. São Paulo: Iglu, 2000, pp. 151-172.

GOULART I.B, Expectativa de Desempenho de Psicólogos em Modernas Organizações. In Psicologia do Trabalho e Gestão de Recursos Humanos: Estudos Contemporâneos. São Paulo: Casa do Psicólogo, 1998.

HUFF, A. S. Mapping Strategic Thought. In A. S. Huff (ed). Mapping Strategic Thought. Chichester: Wiley, 1990, pp.11-49.

LAUKKANEN, M. Comparative Cause Mapping of Management Cognitions. Helsinki: Helsinki School of Economics, 1992.

MARKUS, H. E.; ZAJONC, R. B. The Cognitive Perspective in Social Psychology. In G. Lindzey e E. Aronson (eds.). The Handbook of Social Psychology, 3a. ed, vol. 1. New York: Random House, 1985, pp. 137-230.

MOLINER, P. A Two-dimensional Model of Social Representations. European Journal of Social Psychology, 25, 1995, pp. 27-40. RODRIGUES, A.; ASSMAR, E.M.L.; JABLONSKI, B. Psicologia Social. Petrópolis: Vozes, 19ạ edição, 2000.

ZANELLI, J.C. Movimentos Emergentes na Prática do Psicólogo Brasileiro. In Psicólogo Brasileiro: Práticas Emergentes e Desafios para a Formação. Achcar, R. (org.) São Paulo: Casa do Psicólogo, 1994.

\section{Referências}

